\title{
Maternal folic acid consumption during gestation and its long-term effects on offspring's liver: a systematic review
}

Flavia Bittencourt Brasil 1

Luiz Henrique Amarante 2

Marcos Roberto de Oliveira 3

\footnotetext{
1,2 Departamento de Ciências Naturais. Universidade Federal Fluminense. Rua Recife. s.n. Jardim Bela Vista. Rio das Ostras, RJ, Brasil. CEP: 28.895-532. E-mail: brasil.fb@gmail.com

3 Departamento de Química. Universidade Federal de Mato Grosso. Cuiabá, MT, Brasil.
}

\begin{abstract}
Objectives: describing the effects of maternal supplementation with folic acid (FA) exclusively during gestation on offspring's liver at later stages in life. Supplementation with FA during gestation has been recommended by the medical society worldwide. The liver has a central role on the substances of metabolism and homeostasis and some studies have shown that a high intake of FA at other periods in life may cause hepatic damage.

Methods: a systematic review through which the following databases were consulted: Medline, through platforms of Pubmed, Lilacs and Scielo. The research was performed by keywords such as: "Folic acid", "Gestation", "Rat", "Offspring" and "Liver". Articles which evaluate the effect of FA consumption during both gestation and lactation were excluded.

Results: FA consumption avoids disorders on expression of peroxisome proliferator-activated receptor alpha (PPAR $\alpha)$ and glucocorticoid receptor (GccR), its lack did not change enzyme activity of the male offspring's liver in adulthood. Supplementation with FA during gestation did not change iron hepatic levels or lipid composition, but had an antioxidant effect on it.

Conclusions: supplementation with FA at recommended doses did not cause toxic effects and is very likely to avoid deleterious effects in the liver of the offspring regarding the epigenetic level.
\end{abstract}

Key words Folic acid, Gestation, Liver, Offspring, Rat 


\section{Introduction}

Supplementation with folic acid (FA) during gestation has been recommended by the medical society worldwide. According to the World Health Organization, even in adequate diets, the amount of folic acid is not enough to supply the daily necessities which are getting higher in pregnant women. This can cause anemia, especially in young women. ${ }^{1}$ Suitable diet consumption during gestation is worthwhile for normal developing of offsprings and may determine their metabolic and hormonal status at adulthood.2,3 It was stated that nutritional imbalance during critical periods, such as gestation, may predispose to diseases at adulthood.

The liver has been shown to be an important target organ for metabolic programming in animal models used to demonstrate diseases. Inadquate maternal diet influences this offspring's organ homeostasis and plays a central role on foetal programming. 4

High folic acid consumption during gestation can trigger an increase of body weight and metabolic syndrome of the offspring in later stages of life. 5 It was demonstrated that maternal supplementation with high dose of this vitamin exacerbates the detrimental effects of high fat diets, such as glucose intolerance and insulin resistance, 3 besides changing the peroxisome proliferator activated receptors (PPARs) levels in some foetal tissues when consumed by them during gestation and/or lactation periods. 6

The intake of a high folic acid diet at other periods in life besides gestational, may alter lipid metabolism and cause hepatic damage through hepatocytes degeneration.7 Marsillach et al.8 have demonstrated that when rats received high dose folic acid supplementation for eight to ten weeks, they presented higher amount of collagen, stellate and apoptotic cells on the liver, along with changes in albumin and bilirubin serum levels.

The benefical effects of folic acid consumption by pregnant women are well documented with regards to some parameters, such as offspring's neural tube closing and better learning. In relation to the other organs and systems, there is no consensus in the literature about its benefits. Due to the liver having a central role on the substances of metabolism and homeostasis, it becomes a valuable organ to study effects of several diets and comprehend the metabolic programming.

Therefore, the goal of this study is to determine through a systematic review the effects of maternal supplementation with folic acid exclusively during gestation on the offspring's liver. This study has intended to contribute to the knowledge about the effects of this vitamin on offsprings whose dams have ingested, through previously published studies.

\section{Chemistry and folic acid physiology}

\section{Chemistry}

The folic acid vitamin (pteroylmonoglutamate PteGlu) contains a 2-amino-4-hydroxy-pteridine (pterin, which contains a pyrazine ring) moiety linked to a p-aminobenzoylglutamate moiety through a methylene group. Folate reactions in mammalian cells involve the reduction of its pyrazine ring to the active form called tetrahydrofolate. Additionally, the glutamate chain of folate may be elongated by the addition of glutamate residues. Finally, folate may acquire one-carbon units at N-5 and/or N-10 positions. 9,10 Indeed, folate is a coenzyme that participates of reactions involving the transfer of one-carbon moieties in nucleotide and amino acid metabolism.10,11 In such reactions, folate is found in the folylpolyglutamate form and the polyglutamate chain serves to chanelling the substrates in the active site of the enzyme. Furthermore, such reactions avoid the escape of intermediate products from the protein complex. The tissues retain folylpolyglutamates instead of monoglutamates, which are a form of transport in aqueous systems. 9,12

Folate is not produced by mammalian cells and may be acquired from diet. Microorganisms and plants synthesize the dihydrofolate (DHF) derivative. When reduced folates undergo oxidation, its vitamin activity is affected. Ascorbate (a reducing agent) or absence of oxygen may protect folates from oxidation and inactivation. Actually, ascorbate found in plasma and urine helps to maintain folate in a reduced form. ${ }^{9}$

\section{Physiology}

\subsection{Transport across membranes}

Folates uptake depends on transmembrane transporters to be effective. There are five proteins involved in folate transport across membranes. Two transporters are found in organelles (lysosomes and mitochondria). 13,14

The Reduced Folate Carrier 1 (RFC1) is enconded by the RFCl gene and is a transmembrane anionic exchanger whose activity is higher at physiological pH. RFC1 is a facilitative carrier and its activity is up-regulated by intracellular organic anions. RFC1 is expressed in fetal and adult tissues. Additionally, it is found in cultured cells and some 
tumor cells. RFC is characterized as saturable and has a low affinity for reduced folates (Kt is approximately $3 \mu \mathrm{M}) .15$

The Proton Coupled Folate Transporter (PCFT) functions in acidic $\mathrm{pH}$ and its activity is decreased at physiological $\mathrm{pH}$. Its affinity for folates is higher than that observed on RFC1.16 PCFT is found at high amounts in the small intestine, liver, placenta, brain, and among other tissues. ${ }^{17}$

The Multidrug Resistance-Associated Protein (MRP) also serves as folate exporters from different tissues. However, its affinity for folate is very low (Kt values $0.2-2 \mathrm{mM}$ ). ${ }^{18}$

Mitochondria and lysosomes also possess folate transporters. Mitochondrial transporter is specific for reduced folates (folic acid, for example, is not transported) and the role of lysosomal transporters are not completely understood regarding folates metabolism. 14,19

Folate may also be transported across membranes by three specific receptors (the folate receptors - FR $\alpha, \beta, \gamma)$, which are attached to the plasma membrane through a glycosylphosphatidylinositol anchor.9,20 FR- $\alpha$ is found in the apical membrane facing the circulation in choroid plexus, kidney proximal tubules, ovaries, lung alveolar cells, retinal pigment epithelial cells, and among others. ${ }^{21}$ FR- $\beta$ is expressed in placenta, spleen, and thymus Moreover, FR- $\beta$ is found in fetal tissue. FR $-\gamma$ is expressed in other types of epithelial cells.22 FRs transport folates at slower rates than transmembrane transporters. However, deletion of a gene equivalent to FR- $\alpha$ in a mouse resulted in embryonic death. 20,23 FRs also mediates binding of folates to intracellular proteins responsible for carrying folates in the cytosol.24

\subsection{Intestinal absorption}

Polyglutamate folates obtained from diet are hydrolyzed to monoglutamate forms in the gut and then such mono forms are absorbed by the intestinal mucosa. The enzyme responsible for folylpolyglutamate hydrolysis is a brush-border membrane called $\gamma$-glutamyl hydrolase $(\gamma-\mathrm{GH}, \quad$ or glutamate carboxypeptidase II). After hydrolysis, folate crosses basolateral membrane of mucosal cell and is released into the portal circulation. 9 Intestinal mucosa contains both PCFT and RCF1. Due to the acidic $\mathrm{pH}$ bathing the mucosal cells, folic acid is transported at higher rates as reduced folate monoglutamates by PCFT, which is active at acidic pH (about 5.5).25 In such pH, RCF1 would not be effective in transporting folates, as mentioned above. The release of folates to the portal circulation is believed to occur through the low-affinity, high-capacity MRP3 transporters, since mucosal cells do not express RCF1 or PCFT. 13,25

\subsection{Tissue uptake}

In the mammalian plasma, the major forms of folates circulating are pteroylmonoglutamates (mainly 5-methyl-THF). ${ }^{26}$ Nonetheless, mammalian cells are not able to uptake long chain length of polyglutamates (three and above). ${ }^{27}$ The liver is able to absorb much of the folate that entered the portal circulation. Hepatic cells metabolize folate to polyglutamate derivatives retaining it or releasing it into the blood or bile. 27,28 The folate form that predominates in the plasma (5-methyl-THF) may reflect that this is the major folate form in the cytosol of mammalian cells. In the plasma, folate may be found associated to proteins, as for instance albumin and a soluble form of FR. Such proteins are characterized to bind folates through a low-affinity association. 29

The concentrations of folates are higher in red blood cells than in plasma. 30 Folates may be retained in red blood cells due to its binding to hemoglobin. In the hepatocytes, the transport of folate is ATPdependent. Moreover, basolateral membranes of hepatic cells contain PCFT at high levels in addition to an electroneutral folate- $\mathrm{H}+$ cotransporter that binds reduced and oxidized folates. 28 Peripheral tissues primarily utilize RFC1 to transport folates inside cells. ${ }^{29}$ In the kidney proximal tubules, folate is reabsorbed and virtually no folate is found in the urine at normal folate ingestion conditions. 31

Inside mammalian cells, the major folate derivatives are found as folylpolyglutamate. ${ }^{9}$ The concentration of polyglutamates derivatives is about 10 to $30 \mu \mathrm{M}$ in hepatic cells. ${ }^{32}$ In plasma of humans, folate concentration is found in the range of 10 to $30 \mathrm{nM} .27$ Thus, total folate content in human body has been estimated to be around 10 to $100 \mathrm{mg}$ (3-16 mg in liver).9,26,27 The generation of polyglutamate derivatives occurs in both cytosol and mitochondria and is required to folate accumulation inside cells. 19,33 Folate monoglutamate obtained from plasma may be converted to folylpolyglutamate by the cytosolic enzyme folylpoly- $\gamma$-glutamate synthetase or be transported to mitochondria by the folate transporter found in such organelle. $33 \mathrm{Up}$ to $50 \%$ of cellular folate is transported to mitochondria in some tissues. ${ }^{33}$ Mitochondria utilize folate derivatives in the synthesis and cleavage of glycine and to the degradation of choline. 33,34 A folate pool is also detected in the nucleus and it serves to the thymidylate synthesis.19,35 Folate homeostasis is mainly maintained by the action of folylpoly- $\gamma$-glutamate 
synthetase and $\gamma$-glutamyl hydrolase $\left(\gamma\right.$-GH). ${ }^{36}$ The former is required to generate polyglutamate derivatives leading to the accumulation of such derivatives inside cells (this enzyme is found in both cytosol and mitochondria). 35 The later hydrolyzes polyglutamate chain to folates and is found in the lysosome. ${ }^{37}$ Other enzymes utilize folate derivatives in the onecarbon metabolism, as for instance glycine $\mathrm{N}$ methyltransferase, 10-formyl-THF dehydrogenase, and serine hydroxymethyltransferase. Such enzymes are found at high amounts in liver cells and are called intracellular folate-binding proteins. ${ }^{38}$

Folate excretion occurs mainly through bile (100 $\mu \mathrm{g} /$ day). ${ }^{27,39}$ However, folate is reabsorbed in the small intestine. Furthermore, folate is filtered at the glomerulus and reabsorbed in the proximal renal tubule. No folate is found in urine. Instead, folate cleavage products are observed in the urine. 40

\section{Methods}

We conducted a systematic review, which has been performed by the utilization of different databases from November 2015. In order to obtain more knowledge about the effects of maternal folic acid consumption during gestation on the offspring's liver, scientific articles were published on the following databases: Medline, through the platforms of Pubmed, Lilacs, and Scielo.

In these databases, the research was performed through keywords such as: "Folic acid", "Gestation", "Rat", and "Liver". These descriptors just were used jointly and with the filter AND for advanced searches. 116 articles were obtained, distributed as follows: 34 on Lilacs, 82 on Medline and none on Scielo database.

The study goal was to determine the effects of maternal folic acid consumption specifically on the offspring's liver. The keyword "offspring" to others was added in order to direct papers researched which address the effects upon the offspring. At this phase, 26 articles were obtained, 5 on Lilacs, 21 on Medline and none on the Scielo database.

The following inclusion criteria were applied: (1) only studies with rats or mice, (2) only studies that have shown the effects of maternal consumption of folic acid on the offspring's liver. On the other hand, exclusion criteria were as follows: (1) studies which evaluate the effect of folic acid consumption during gestation associated to any disease; (2) studies that evaluate maternal folic acid consumption during gestation and lactation or only during lactation and (3) articles that assess the folic acid consumption by their own offspring.

Applying such criteria, 5 articles were excluded because they appeared repeatedly in different databases, 4 were eliminated because evaluated intake of folic acid in different phases in life or was associated to another experimental model and 1 which assessed the effects on dams instead of on the offspring. 2 studies were excluded because evaluated folic acid with the purpose of determing the effect on gestational hypertension and the last one assessed the folic acid intake by their own offspring. Finally, 3 papers were not regarded because of the lack of ability to verify the effect of folic acid on different parameters or tissues. Therefore, 11 articles were selected for this study, all being experimental works and whereby we extracted our results.

\section{Results}

The papers that have composed the sample of our study relate several effects of maternal supplementation with folic acid only during gestational period. Such effects are arranged by categories.

\section{Effects of folic acid on the offspring's liver at molecular parameters}

Maloney et al. 41 have studied the effects of a folic acid-deficient diet during early gestation and have demonstrated that it did not alter mRNA levels to glyceraldehyde-3-phosphate dehydrogenase (GAPDH), peroxisome proliferator-activated receptor alpha $(\operatorname{PPAR} \alpha)$, PPAR-gamma and glucocorticoid receptor (GccR) on male offsprings at six months of age.

According to those authors, it seems that event programming hepatic fat metabolism through PPAR isoforms, at least, occur later in foetal development and maternal deprivation of folic acid at early gestation does not change those proteins.

Recently, some studies have also investigated if folic acid supplementation is able to protect against detrimental effects of others nutritional disorders, such as under nutrition. For this purpose, Lillycrop et al. 42 evaluated whether the effects of the maternal protein-restricted diet can be ameliorated by supplementing it with folic acid exclusively during gestation in the offspring's liver. These authors found that supplementation of the protein restricted diet with folic acid prevented hypomethylation of GR and PPAR $\alpha$, and the associated increase in the expression of GR and PPAR $\alpha$. 
Besides this, PPAR $\alpha$ and GR receptor expression did not differ between the offspring of the control group and protein restricted with folic acid dams. It seems that folic acid consumption protects against harmful effects of deficient protein diet, avoiding disorders on expression of these receptors and metabolic alterations.

Meher et al.43 evaluated the expression of several transcription factors and levels of global methylation on the offsprings' liver of dams fed with folic acid deficient diet during gestation. There was a reduction on the absolute weight of the liver along with changes on hepatic transcription factors and higher global DNA methylation.

These same authors comment that folate, as well as vitamin $\mathrm{B} 12$ regulate $\mathrm{S}$-adenosyl methionine (SAM) generation, a molecule which is the universal methyl donor and crucial for many reactions and any change on it may promote disturbances on essential mechanisms, for instance, cell proliferation.

\section{Effects of folic acid on offspring's liver at enzimatic/protein levels}

Maloney et al. 41 have demonstrated that the level of proteins classified into three main groups, such as proteins associated with energy metabolism, antioxidant defence and amino acid and peptide metabolism were changed in the livers of the male offspring whose dams received folic acid deficient diet at 6 and 12 months of age.

There was also alteration on GAPDH levels on the offspring's liver whose dams received FA deficient diet at 6 months of age. Although GAPDH is mainly known for its role in glycolysis, there is evidence to suggest that this protein is involved in the control of proliferation, apoptosis and transcription. 44

On the other hand, Maloney et al.41 demonstrated that enzyme activity of male offspring's liver from dams fed with FA deficient diet during the first five days of gestation was unchanged in these animals at 6 months. This paper suggests that the lack of FA on maternal diet at early gestation does not change this parameter in adulthood.

\section{Effects of folic acid on offspring's liver at mineral amount and lipid composition}

Król et al. 45 have shown that supplementation with FA during gestation did not change iron hepatic levels of the offspring. It seems that folic acid maternal supplementation was not able to change the mineral status of the young offspring.

In regards to hepatic lipid composition, maternal FA intake did not alter in the adult offspring. Burdge et al. 46 suggest that gender can determine differences in liver phospholipid fatty acid composition, but not maternal folic acid consumption.

\section{Protective and antioxidant effect of folic acid on the offspring's liver}

Ojeda et al. ${ }^{47}$ demonstrated that a supplemented diet with selenuim (Se) plus folic acid to ethanol-exposed dams is able to restore Se pancreas concentration to a control status and displaces Se to the liver and brain. These authors related that exposure to ethanol during gestation decreases the levels of these nutrients and it disrupts oxidative balance. 47

The chronic use of ethanol during pregnancy causes oxidative stress and liver disorder in the mother and her progeny by increasing the specific activity of glutathinone redutase (GR). This damage can be prevented by treatment of the pregnant mother with FA associated to selenium that reduces GR activity and increases glutathione levels. 48,49

\section{Discussion}

According to the results of this review, folic acid can protect against harmful effects of maternal protein restriction during gestation. When dams submitted to protein restriction during gestation receive higher doses of folic acid, hypomethyilation of dinucleotides in the PPAR $\alpha$ promoter is prevented. Such hypomethylation occurs on liver offspring whose mothers were fed on low protein diet and lower doses of folic acid. Hypomethylation and the resulting increase in PPAR $\alpha$ expression was prevented, reinforcing protective effect of folic acid. 50 PPAR activities are central to lipid and carbohydrate homeostasis. ${ }^{51}$

However, two other specific dinucleotides were hypermethylated in the offspring whose dams received higher doses of folic acid, which suggests that increased maternal folic acid intake can cause subtle effects, but may still alter gene function. 50 These results confirm that alterations in the amount of specific nutrients in the maternal diet during pregnancy modify the metabolic phenotype of the offspring.

Hyper or hypomethylation processes may lead to alterations on gene transcription and as consequence, change the cellular metabolism. As peroxisome proliferator-activated receptor $\alpha(\operatorname{PPAR} \alpha)$ is a nuclear receptor protein expressed in the liver and 
other tissues that play essential roles in the regulation of cellular differentiation, development and metabolism of carbohydrate, protein and lipid, besides tumorigenesis of higher organisms, 52 any change involving such receptor can be harmful and determine long-term diseases by changing the metabolic profile.

Any change in gene expression is critical for normal cell differentiation and embryogenesis. 53 DNA methylation patterns are largely established in the uterus, and any change on fetal environment may alter DNA methylation, inducing stable changes in gene expression that can be sustained throughout the life of an individual and constitute the origin of diseases. ${ }^{42}$ Some studies have proposed that methyl donor deficiency (folate) changes DNA methylation models and initiates hypomethylation in the liver and other tissues. 43

Gong et al. 54 analyzed insulin-like growth factor II (Igf2) expression on the male offspring's liver. Igf 2 works as a mediator in the liver and brain to respond to prenatal dietary manipulations, stress such as choline deficiency, or supplementation. 55 These authors found that in the group of dams fed on low protein diet with folic acid supplement, the Igf2 mRNA expression was similar to the level of the control group. In the same way, epigenetic modification was avoided in the offspring's liver following maternal supplementation with folic acid. These results suggest that maternal folic acid supplementation can reverse the effects from maternal low protein intake during pregnancy.

Several proteins, including GAPDH can be changed by maternal FA deficiency. These results reinforce that the absence of this vitamin in the maternal diet at the early period of gestation or any nutritional disorder are critical and programming is altered in several cellular processes that remain long term, extending until adulthood. In this regard, the availability of folic acid at early phases of embryogenesis seems important.

Regarding minerals, FA supplementation during gestation did not change iron hepatic levels of the offspring. This fact is favorable, due to oral supplementation with elemental iron $(60 \mathrm{mg} /$ day $)$, alone or with folic acid, is useful to treat irondeficiency anemia in pregnant women ${ }^{56}$ and can reduce the rate of preterm birth. 57

Finally, the examined papers have showed that supplementation of folic acid plus Se can reduce the oxidative stress and has a protective effect. 47 FA prevents peroxidation protein products and neutralizes the damage of ethanol consumption during gestation. 48,49 This defense property is given through the ability of FA to increase glutathione levels on tissues, since glutathione is the most important scavenger-endogenous of the free radicals. Folic acid can reverse apoptosis and cell damage caused by toxic agents. 58

Using rats with streptozotocin-induced diabetes, Zal et al. 59 have shown that systemic administration of FA, when associated to vitamin E (VE), can prevent oxidative damage and apoptosis in the uterus of these animals. The authors suggested that pharmacology effects associated to FA and VE are related with the increase of levels of the glutathione and with decreased of the malondialdehyde, 59 reinforcing the protective effect of folic acid.

\section{Final Considerations}

The studies analyzed here have shown that maternal diet supplementation with folic acid during gestation brings benefits in adverse conditions, such as alcohol consumption and protein deprivation. It exerts a protective effect, such as avoiding deleterious epigenetic changes on the offspring's liver which could initiate many diseases in adulthood. Furthermore, folic acid enhanced defenses in mammalian cells.

Besides being needed during pregnancy, supplementation with FA did not cause toxic effects at recommended doses. Moreover, FA and its analogs can prevent the damages caused by potentially toxic drugs such as methotrexate, 5fluorouracil, and other antifolate drugs used for treatment of several diseases. 60

Because folic acid is widely used during gestation and even before it, more studies are needed in order to clarify the impact of maternal folic acid consumption on offspring's metabolism, not only on the liver, but in other crucial organs, such as the kidney. Studies that report morphological alterations caused by this vitamin, for example, are scarce and might be worth analyzing to reveal its effects on several tissues.

Due to relevance, our group has focused on knowing the effects of total absence, normal and overdose consumption of folic acid during gestation on adult offspring by morphologic changes in the structures related to metabolism as cited above, since unsuitable maternal nutrition can trigger several impairments to the offspring's health. 


\section{References}

1. Hediger ML, Scholl, TO, Khoo CS, Fischer RL. Diet, weight gain, and circulating micro-nutrients: Evidence for nutritional depletion following adolescent pregnancy. J Adolesc Health. 1992; 13 (1): 46

2. Brasil FB, Faria TS, Costa WS, Sampaio FJB, Ramos CF. The pups' endometrium is affected by maternal malnutrition during suckling. Maturitas. 2005; 51: 405-12.

3. Huang Y, He Y, Sun X, He Y, Li Y, Sun C. Maternal High Folic Acid Supplement Promotes Glucose Intolerance and Insulin Resistance in Male Mouse Offspring Fed a HighFat Diet. Int J Mol Sci. 2014; 15(4): 6298-313.

4. Maloney CA, Hay SM, Reid MD, Duncan G, Nicol F, Sinclair KD, Rees WD. A methyl-deficient diet fed to rats during the pre- and peri-conception periods of development modifies the hepatic proteome in the adultoffspring. Genes Nutr. 2013; 8 (2): 181-90.

5. Pannia E, Cho CE, Kubant R, Sánchez-Hernández D, Huot PS, Chatterjee D, Fleming A, Anderson GH. A high multivitamin diet fed to Wistar rat dams during pregnancy increases maternal weight gain later in life and alters homeostatic, hedonic and peripheral regulatory systems of energy balance. Behav Brain Res. 2015; 278: 1-11.

6. Sie KK, Li J, Ly A, Sohn KJ, Croxford R, Kim YI. Effect of maternal and postweaning folic acid supplementation on global and gene-specific DNA methylation in the liver of the rat offspring. Mol Nutr Food Res. 2013; 57 (4): 677-85.

7. Christensen KE, Mikael LG, Leung K, Lévesque N, Deng L, Wu Q, Malysheva OV, Best A, Caudill MA, DE Greene N, Rozen R. High folic acid consumption leads to pseudoMTHFR deficiency, altered lipid metabolism, and liver injury in mice. Am J Clin Nutr. 2015; 101 (3): 646-58.

8. Marsillach J, Ferré N, Camps J, Riu F, Rull A, Joven J. Moderately high folic acid supplementation exacerbates experimentally induced liver fibrosis in rats. Exp Biol Med (Maywood). 2008; 233 (1): 38-47.

9. McGuire JJ, Coward JK. Pteroylpolyglutamates: Biosynthesis, degradation, and function. In: Blakley RL, Benkovic SJ, editor. Folates and Pterins. Chemistry and Biochemistry of Folates. New York: John Wiley \& Sons; 1984. p. 135-90

10. Shane B. Folylpolyglutamate synthesis and role in the regulation of one-carbon metabolism. Vitam Horm. 1989; 45: 263-335.

11. Shane B, Stokstad EL. Vitamin B12-folate interrelationships. Annu Rev Nutr. 1985; 5: 115-41.

12. Stokstad ELR. Historical perspective on key advances in the biochemistry and physiology of folates. In: Picciano MF, Stokstad ELR, Gregory JF, editor. Contemporary Issues in Clinical Nutrition. Folic Acid Metabolism in Health and Disease. New York: Wiley-Liss; 1990. p. 1-21.

13. Sirotnak FM, Tolner B. Carrier-mediated membrane transport of folates in mammalian cells. Annu Rev Nutr. 1999; 19: $91-122$.

14. Titus SA, Moran RG. Retrovirally mediated complementation of the glyB phenotype. Cloning of a human gene encoding the carrier for entry of folates into mitochondria. J Biol Chem. 2000; 275 (47): 36811-817.
15. Zhao R, Gao F, Goldman ID. Reduced folate carrier transports thiamine monophosphate: An alternative route for thiamine delivery into mammalian cells. Am J Physiol Cell Physiol. 2002; 282 (6): C1512-517.

16. Zhao R, Matherly LH, Goldman ID. Membrane transporters and folate homeostasis: Intestinal absorption and transport into systemic compartments and tissues. Expert Rev Mol Med. 2009; 11:e4.

17. Zhao R, Min SH, Qiu A, Sakaris A, Goldberg GL, Sandoval C, Malatack JJ, Rosenblatt DS, Goldman ID. The spectrum of mutations in the PCFT gene, coding for an intestinal folate transporter, that are the basis for hereditary folate malabsorption. Blood. 2007; 110 (4): 1147-52.

18. Assaraf YG. The role of multidrug resistance effl ux transporters in antifolate resistance and folate homeostasis. Drug Resist Update. 2006; 9 (4-5): 227-46.

19. Appling DR. Compartmentation of folate-mediated onecarbon metabolism in eukaryotes. FASEB J. 1991; 5 (12): 2645-651.

20. Matherly LH, Goldman ID. Membrane transport of folates. Vitam Horm. 2003; 66: 403-56.

21. Kamen BA, Smith AK. A review of folate receptor alpha cycling and 5-methyltetrahydrofolate accumulation with an emphasis on cell models in vitro. Adv Drug Deliv Rev. 2004; 56 (8): 1085-97.

22. Weitman SD, Weinberg AG, Coney LR, Zurawski VR, Jennings DS, Kamen BA. Cellular localization of the folate receptor: potential role in drug toxicity and folate homeostasis. Cancer Res. 1992; 52 (23): 6708-711.

23. Taparia S, Gelineau-van Waes J, Rosenquist TH, Finnell $\mathrm{RH}$. Importance of folate-homocysteine homeostasis during early embryonic development. Clin Chem Lab Med. 2007; 45 (12): 1717-27.

24. Elnakat H, Ratnam M. Role of folate receptor genes in reproduction and related cancers. Front Biosci. 2006; 11: 506-19.

25. Qiu A, Jansen M, Sakaris A, Min SH, Chattopadhyay S, Tsai E, Sandoval C, Zhao R, Akabas MH, Goldman ID. Identification of an intestinal folate transporter and the molecular basis for hereditary folate malabsorption. Cell. 2006; 127 (5): 917-28.

26. Clifford AJ, Heid MK, Muller HG, Bills ND. Tissue distribution and prediction of total body folate of rats. J Nutr. 1990; 120 (12): 1633-9.

27. Whitehead VM. Pharmacokinetics and physiological disposition of folate and its derivatives. In: Blakley RL, Whitehead VM, editor. Folates and Pterins. Chemistry and Biochemistry of Folates. New York: John Wiley \& Sons; 1986. p. 177-205.

28. Horne DW, Reed KA, Hoefs J, Said HM. 5Methyltetrahydrofolic acid transport in basolateral membrane vesicles from human liver. Am J Clin Nutr. 1993; 58 (1): 80-4.

29. Ratnam M, Freisheim JH. Proteins involved in the transport of folates and antifolates by normal and neoplastic cells. In: Picciano MF, Stokstad ELR, Gregory JF, editor. Contemporary Issues in Clinical Nutrition. Folic Acid 
Metabolism in Health and Disease. New York: Wiley-Liss; 1990. p. 91-120.

30. Lin Y, Dueker SR, Follett JR, Fadel JG, Arjomand A Schneider PD, Miller JW, Green R, Buchholz BA, Vogel JS, Phair RD, Clifford AJ. Quantitation of in vivo folate metabolism. Am J Clin Nutr 2004; 80 (3): 680-91.

31. Selhub J, Emmanouel D, Stavropoulos T, Arnold R. Renal folate absorption and the kidney folate binding protein. I. Urinary clearance studies. Am J Physiol. 1987; 252(4): $750-56$

32. Cassady IA, Budge MM, Healy MJ, Nixon PF. An inverse relationship of rat liver folate polyglutamate chain length to nutritional folate sufficiency. Biochim Biophys Acta. 1980; 633 (2): 258-68.

33. Lin BF, Huang RF, Shane B. Regulation of folate and one carbon metabolism in mammalian cells. III. Role of mitochondrial folylpolyglutamate synthetase. J Biol Chem. 1993; 268: 21674-9.

34. Lowe KE, Osborne CB, Lin BF, Kim JS, Hsu JC, Shane B. Regulation of folate and one carbon metabolism in mammalian cells. II. Effect of folylpolyglutamate synthetase substrate specificity and level on folate metabolism and folylpolyglutamate specifi city of metabolic cycles of one carbon metabolism. J Biol Chem. 1993; 268: 21665 73.

35. Chen L, Qi H, Korenberg J, Garrow TA, Choi YJ, Shane B. Purification and properties of human cytosolic folylpoly- $\gamma$ glutamate synthetase and organization, localization, and differential splicing of its gene. J Biol Chem. 1996; 271 (22): 13077-87.

36. Moran RG, Colman PD. Measurement of folylpolyglutamate synthetase in mammalian tissues. Anal Biochem. 1984; 140 (2): 326-42.

37. Whitehead VM, Kalman TI, Vuchich MJ. Inhibition of gamma-glutamyl hydrolases in human cells by 2 -mercaptomethylglutaric acid. Biochem Biophys Res Commun. 1987; 144 (1): 292-7.

38. Anguera MC, Field MS, Perry C, Ghandour H, Chiang EP, Selhub J, Shane B, Stover PJ. Regulation of folate-mediated one-carbon metabolism by 10 -formyltetrahydrofolate dehydrogenase. J Biol Chem. 2006; 281 (27): 18335-42.

39. Suh JR, Herbig AK, Stover PJ. New perspectives on folate catabolism. Annu Rev Nutr. 2001; 21: 255-82.

40. Williams WM, Huang KC. Renal tubular transport of folic acid and methotrexate in the monkey. Am J Physiol. 1982 242 (5): 484-90

41. Maloney CA, Hay SM, Reid MD, Duncan G, Nicol F, Sinclair, KD, Rees WD. A methyl-deficient diet fed to rats during the pre- and peri-conception periods of development modifies the hepatic proteome in the adult offspring. Genes Nutr. 2013; 8 (2): 181-90

42. Lillycrop KA, Phillips ES, Jackson AA, Hanson MA, Burdge GC. Dietary protein restriction of pregnant rats induces and folic acid supplementation prevents epigenetic modification of hepatic gene expression in the offspring. $\mathrm{J}$ Nutr. 2005; 135 (6): 1382-6.

43. Meher A, Joshi A, Joshi S. Differential regulation of hepatic transcription factors in the Wistar rat offspring born to dams fed folic acid, vitamin B12 deficient diets and supple- mented with omega-3 fatty acids. PLoS One. 2014; 9 (2): e90209.

44. Nicholls C, Li H, Liu JP. GAPDH: a common enzyme with uncommon functions. Clin Exp Pharmacol Physiol. 2012; 39(8): 674-9.

45. Król E, Krejpcio Z, Chmurzynska A. Folic acid and protein content in maternal diet and postnatal high-fat feeding affect the tissue levels of iron, zinc, and copper in the rat. Biol Trace Elem Res. 2011; 144 (1-3): 885-93.

46. Burdge GC, Slater-Jefferies JL, Grant RA, Chung WS, West AL, Lillycrop KA, Hanson MA, Calder PC. Sex, but not maternal protein or folic acid intake, determines the fatty acid composition of hepatic phospholipids, but not of triacylglycerol, in adult rats. Prostaglandins Leukot Essent Fatty Acids. 2008; 78 (1): 73-9.

47. Ojeda ML, Jotty K, Nogales F, Murillo ML, Carreras O. Selenium or selenium plus folic acid intake improves the detrimental effects of ethanol on pups' selenium balance. Food Chem Toxicol. 2010; 48 (12): 3486-91.

48. Ojeda ML, Nogales F, Jotty K, Barrero MJ, Murillo ML, Carreras O. Dietary selenium plus folic acid as an antioxidant therapy for ethanol-exposed pups. Birth Defects Res B Dev Reprod Toxicol. 2009; 86 (6): 490-5.

49. Cano MJ, Ayala A, Murillo ML, Carreras O. Protective effect of folic acid against oxidative stress produced in 21day postpartum rats by maternal-ethanol chronic consumption during pregnancy and lactation period. Free Radic Res. 2001; 34 (1): 1-8

50. Lillycrop KA, Phillips ES, Torrens C, Hanson MA, Jackson AA, Burdge GC. Feeding pregnant rats a protein-restricted diet persistently alters the methylation of specific cytosines in the hepatic PPAR alpha promoter of the offspring. Br J Nutr. 2008; 100 (2): 278-82.

51. Djouadi F, Weinheimer CJ, Saffitz JE, Pitchford C, Bastin, J, Gonzalez FJ, Kelly DP. A gender-related defect in lipid metabolism and glucose homeostasis in peroxisome proliferator-activated receptor alpha-deficient mice. J Clin Invest. 1998; 102 (6): 1083-91

52. Berger J, Moller DE. The mechanisms of action of PPARs. Annu Rev Med. 2002; 53: 409-35.

53. Razin A, Shemer R. DNA methylation in early development. Hum Mol Genet. 1995; 4 (1): 1751-5.

54. Gong L1, Pan YX, Chen H. Gestational low protein diet in the rat mediates Igf2 gene expression in male offspring via altered hepatic DNA methylation. Epigenetics. 2010; 5 (7): 619-26.

55. Napoli I, Blusztajn JK, Mellott TJ. Prenatal choline supplementation in rats increases the expression of IGF2 and its receptor IGF2R and enhances IGF2- induced acetylcholine release in hippocampus and frontal cortex. Brain Res. 2008; 1237: $124-35$.

56. Meier PR, Nickerson HJ, Olson KA, Berg RL, Meyer JA. Prevention of Iron Deficiency Anemia in Adolescent and Adult Pregnancies. Clin Med Res. 2003; 1 (1): 29-36.

57. Bánhidy F, Acs N, Puhó EH, Czeizel AE. Iron deficiency anemia: Pregnancy outcomes with or without iron supplementation. Nutrition. 2011; 27 (1): 65-72.

58. Abilés J, Moreno-Torres R, Moratalla G, Castaño J, Pérez Abúd R, Mudarra A, Machado MJ, Planells E, Pérez de La 
Cruz A. Efectos de la suplementación con glutamina sobre el sistema antioxidantey la peroxidación lipídica en pacientes críticos con nutrición parenteral. Nutr Hosp. 2008; 23 (4): 332-9.

59. Zal F, Mahdian Z, Zare R, Soghra B, Mostafavi-Pour Z. Combination of vitamin $\mathrm{E}$ and folic acid ameliorate oxidative stress and apoptosis in diabetic rat uterus. Int J Vitam Nutr Res. 2014; 84 (1-2): 55-64.
60. Grem JL. Systemic treatment options in advanced colorectal cancer: perspectives on combination 5-fluorouracil plus leucovorin. Semin Oncol. 1997; 24 (5 Suppl. 18): S18-8-S18-8.

Received on August 11, 2016

Final version presented on February 9, 2017

Approved on February 17, 2017 